Frauenärztliche Taschenbicher

Herausgeber: W. Straube und Th. Römer 



\section{Ralf Ohlinger}

Invasive Mammadiagnostik

Stanzbiopsie, Drahtmarkierung,

Präparatsonographie 
OA Dr. med. R. Ohlinger

Ernst-Moritz-Arndt-Universität Greifswald

Klinik und Poliklinik

für Frauenheilkunde und Geburtsmedizin

Wollweberstraße 1-3

17487 Greifswald

\section{Das Buch enthält 121 Abbildungen}

Die Deutsche Bibliothek - CIP-Einheitsaufnahme

Ohlinger, Ralf:

Invasive Mammasonographie : Stanzbiopsie, Drahtmarkierung,

Präparatsonographie / Ralf Ohlinger. - Berlin ; New York : de Gruyter, 2002

(Frauenärztliche Taschenbücher)

ISBN 3-11-017274-7

(C) Copyright 2001 by Walter de Gruyter GmbH \& Co. KG, D-10785 Berlin.

Dieses Werk einschließlich aller seiner Teile ist urheberrechtlich geschützt. Jede Verwertung außerhalb der engen Grenzen des Urheberrechtsgesetzes ist ohne Zustimmung des Verlages unzulässig und strafbar. Das gilt insbesondere für Vervielfältigungen, Übersetzungen, Mikroverfilmungen und die Einspeicherung und Verarbeitung in elektronischen Systemen.

Der Verlag hat für die Wiedergabe aller in diesem Buch enthaitenen Informationen (Programme, Verfahren, Mengen, Dosierungen, Applikationen etc.) mit Autoren und Herausgebern große Mühe darauf verwandt, diese Angaben genau entsprechend dem Wissensstand bei Fertigstellung des Werkes abzudrucken. Trotz sorgfältiger Manuskripterstellung und Korrektur des Satzes können Fehler nicht ganz ausgeschlossen werden. Autoren bzw. Herausgeber und Verlag übernehmen infolgedessen keine Verantwortung und keine daraus folgende oder sonstige Haftung, die auf irgendeine Art aus der Benutzung der in dem Werk enthaltenen Informationen oder Teilen davon entsteht.

Die Wiedergabe von Gebrauchsnamen, Handelsnamen, Warenbezeichnungen und dergleichen in diesem Buch berechtigt nicht zu der Annahme, dass solche Namen ohne weiteres von jedermann benutzt werden dürfen. Vielmehr handelt es sich häufig um gesetzlich geschützte, eingetragene Warenzeichen, auch wenn sie nicht eigens als solche gekennzeichnet sind.

Textkonvertierung: I. Ullrich, Berlin - Druck und buchbinderische Verarbeitung: Druckhaus Thomas Müntzer $\mathrm{GmbH}$, Bad Langensalza - Umschlagentwurt: Rudolf Hübler, Berlin

Printed in Germany 